\title{
Role of the agency theory in implementing management's control
}

\author{
Mohammad Namazi \\ Department of Accounting, College of Economics, Management and Social Science, Shiraz University, Iran.
}

Accepted 15 March, 2012

\begin{abstract}
The major purpose of this article is to analyze the role of the "Agency Theory" in implementing effective control mechanisms. In effect, various control paradigms under the following situations are elaborated: a) When the agent's control system is merely based on the output under the condition of uncertainty; b) When the control mechanism is based on the output, and information about agent's action or effort; c) When the agent's monitoring control is based on the output, agent's action and additional variables. It is concluded that agency theory posits different organizational, behavioral, economical and controlling roles, and it is a potent framework which can be extricated in promulgation of the management control systems. Furthermore, the implementation of a control mechanism depends on the amount and contents of the public and/ or private information that exist in the domain of the managerial accounting system. The disseminated information and the concurrent variables surrounding the agency relations are also vital elements in creating any control system. Finally, the optimal control mechanism under each preceding conditions are revealed.
\end{abstract}

Key words: Agency theory, management control, accounting information systems, information asymmetry.

\section{INTRODUCTION}

According to the management accounting literature (Zimmerman, 2010; Kaplan and Atkinson, 2012; Horngren, et al., 2012) one of the significant functions and responsibilities of the managers is exerting control over the firms' operations and resources. The classic definition of management control posits control as "the process by which managers assure that resources are obtained and used effectively in the accomplishment of the organization's objectives", (Anthony, 1965: 17).

Today, however, the domain of control has been extended to consider not only the operations and strategic positions of the company, but also contemplating behavioral issues, and providing incentives to employees. In essence, a suitable management accounting system should dovetail the "planning" and "control" system in such a manner to provide information concerning accountability, and feedback information to ensure that the company adapts the internal and external organizational and environmental changes, the employees' behavior, and measurement of the firm's variances from the actual operations. Figure 1 demonstrates the elements of this system.

Figure 1 indicates that the major elements of a suitable management control system really consist of two cycles: 1) the strategic planning cycle, and 2) the control cycle (Horngren et al., 2012). The strategic planning cycle encompasses establishing long-term and short-term strategic objectives, measures and targets, and related standards and budgets. The control cycle consists of the components which are illustrated in Figure 1. Hence, the control cycle is started based upon the designated strategic planning. The feedback is the central focus of the control system since it obtains information from the strategic planning process and particularly from the standards and budgets- element that makes it possible to compare actual results with standards and budgets and to determine concurrent variances. The final step of the control cycle leads to assimilating relevant information for 


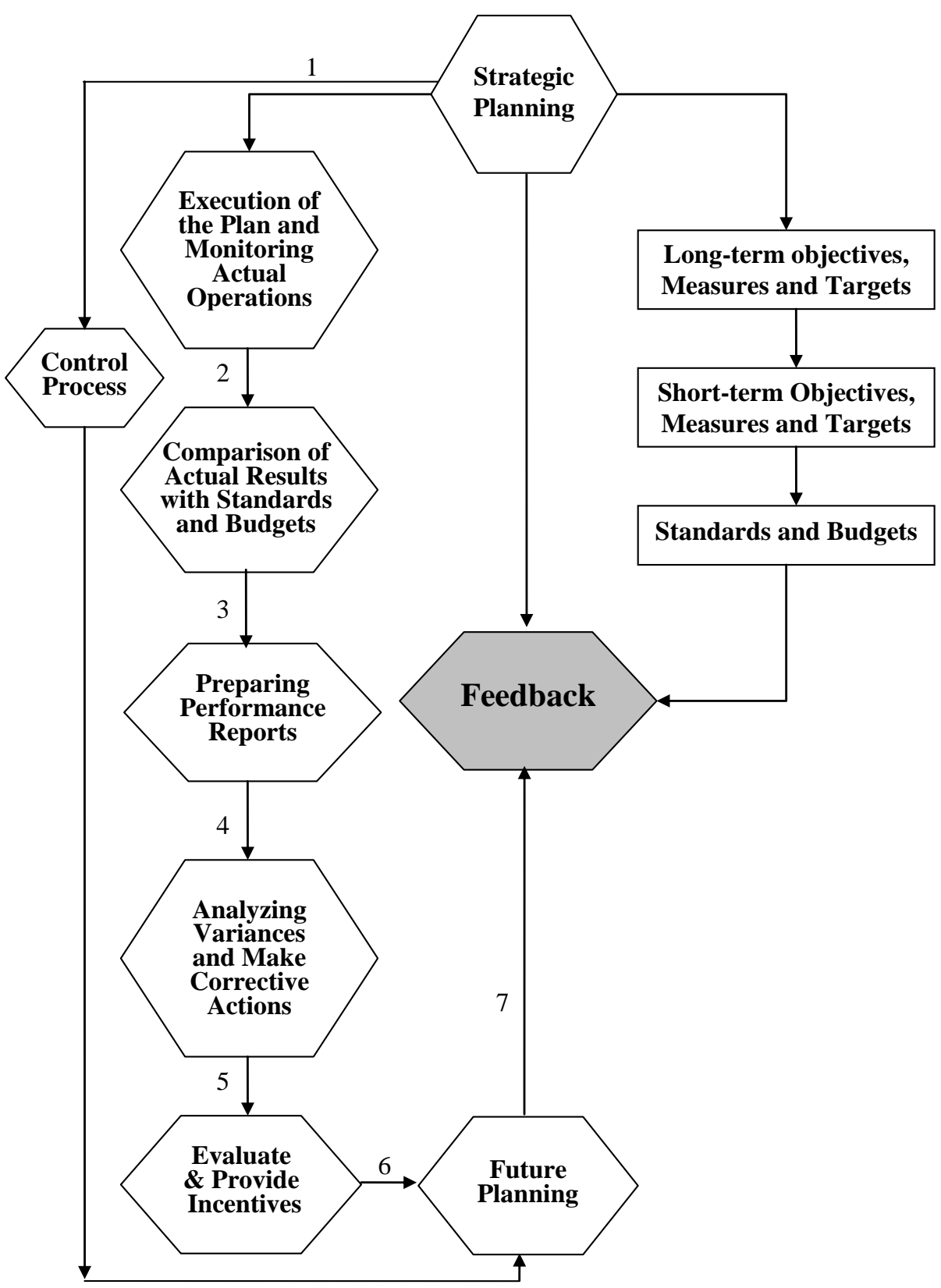

Figure 1. Major elements of the management control system.

future planning and it is also referred to the feedback component (Zimmerman, 2010).

Hence, in implementing a successful control system, many issues are significant, particularly the following: (Outley, 2006: 49)

1) What are the "performance criteria" that will represent suitable performance?

2) What are the "relevant standards" of performance?

3) What are the rewards, and "behavioral issues" that will lead to the successful attainment of the targets and objectives?
In effect, the major inquiry is: How can efficient control mechanisms be designed and implemented in order to attain the goals and/or objectives of the firms? And at the same time provide incentives to firms' individuals to adapt actions that would lead to the attainment of the goal congruency?

The major purpose of this article is to demonstrate that the proceeding inquiry can be addressed effectively via the agency theory paradigms (Baiman, 1982; Lan and Heracleous, 2010). In effect, it investigates the role of the agency theory in devising optimal-incentive control systems. The contributions of this investigation are as 
follows:

1) It provides a comprehensive explanation concerning the delicate performance criteria under the uncertainty condition.

2) It explicitly and mathematically demonstrates relevant components of the significant variables and standards of the optimal control systems.

3) It quantitatively extricates the significance of contemplating rewards and behavioral issues in designing optimal-incentive control frameworks.

4) It unambiguously delineates the importance of pecuniary as well as non-pecuniary factors in implementing efficient control systems.

The organization of this article is as follows: the methodology of the study; the basic agency theory model; management's control via the basic agency paradigms; findings of the study under various control mechanisms; discussion and concluding remarks.

\section{METHODOLOGY}

The methodology of this study is based upon implementation of the "agency theory" framework. This theory, as will be explained later, has demonstrated a potent potential for establishing management control systems, because it is rich and mathematically considers various pecuniary and non-pecuniary items existing in the control systems. In addition, this theory is selected because various accounting scholars (Dikolli, 2001; Eldenburg and Krishnan, 2003; Kren and Tyson, 2009) have discussed its significance for establishing efficient management control devices. They also have shown that agency theory is able to explain the holistic as well as embedded effects of the control issues, and has an extensive ability to capture various control mechanisms under the condition of uncertainty. The latter aspect is particularly important, since most management control variables are usually uncontrollable and would happen under uncertain conditions. Furthermore, given accounting information systems, agency theory designates the exact managements' control variables precisely, and determines the optimal control elements which could be established under various control situations. It also considers the behavior and motivational issues in establishing control mechanisms. In sum, no other theories is as rich as the agency theory in explaining the reasons for developing managements' control systems, considering their elements, and how they can be effective established in various organizations.

\section{BASIC AGENCY THEORY}

Basic agency paradigm was developed in the economics literature during 1960s and 1970s in order to determine the optimal amount of the risk- sharing among different individuals (Spence and Zeckhauser, 1971; Ross, 1973; Jensen and Meckling, 1976; Harris and Raviv 1976, 1978; Holmstrom, 1979).

However, gradually the domain of the agency theory was extended to the management area for determining the cooperation between various people with different goals in the organization, and attainment of the goal congruency (Eisenhardt, 1989). In 1980s, agency theory was also appeared extensively in the managerial accounting realms to determine the optimal-incentive contracting among different individuals and establishing suitable accounting control mechanisms to monitor their behaviors and actions (Demski, 1980; Biaman, 1982; Namazi, 1985). It is this last function of the agency theory that will be emphasized in this study.

In its primitive form, agency theory relates to situations in which one individual (called the agent) is engaged by another individual (called the principal) to act on his/her behalf based upon a designated fee schedule. Since both individuals are assumed to be utility maximizer, and motivated by pecuniary and non-pecuniary items, incentive problems may arise, particularly under the condition of uncertainty and informational asymmetry. That is, the objective function of the principal and the agent may be incompatible, and therefore, the agent may take actions which will jeopardize the principal's benefits.

In addition, an agency operates under the condition of risk and uncertainty. In effect, the basic agency theory usually assumes that both individuals are risk averse. Under this circumstances, the amount and content of the produced accounting information and other information sources would become a significant issue in risk sharing and controlling the agent's actions (Namazi, 1985; Baiman, 1982, 1990).

The preceding basic agency model, however, has also been extended to cases in which there are multiple agents (Holmstrom, 1979; Antle, 1982; Radner, 1981), private information (Penno, 1984), multiple period performance (Radner, 1981), and multi-objective models (Namazi, 1983). In addition, the effect of various cultures on the assumptions of the agency theory has also been investigated (Osterman, 2006; Kren and Tyson, 2009).

Given the agency theory paradigm, and following Alchian and Demsetz (1972), Jensen and Meckling (1972), and Kaplan (1984), among others, a firm can be characterized as a nexuses of contractual agreements among different individuals. In this view, contracts are considered as an appropriate means for resource allocation and revealing the scope of the firm's activities. In addition, they can be expended as a powerful framework for effective management accounting control mechanisms. In this context, performance measures, appropriate control variables, and exogenous and endogenous parameters affecting the control process, can be captured and specified quantitatively by adapting the "agency theory" framework. Hence, this study draws in the agency paradigms to investigate the role of the agency theory in establishing management's control.

\section{MANAGEMENTS' CONTROL VIA THE BASIC AGENCY PARADIGM}

To illustrate the basic elements of a control model in 
terms of the agency framework, consider a simple firm which consists of two individuals only; one individual is the owner (called principal), the other one is the manager (called the agent). The principal has invested in the firm, and has delegated the responsibility of the decision making to the agent. The agent exerts his/her services based upon pre-specified contractual agreements. Since the agent is motivated primarily by his/her self interest, he may select actions which would jeopardize the principal's benefits. To prevent the agent, a suitable control mechanism must be established. Thus, agency theory provides a potent reason as to why maintaining control mechanisms is necessary. We define this role as "the organizational role" of the agency.

Let us assume the final outcome (revenues, profits, etc.) resulting from the firm's operations is $x \in X$. The manager's share is $x_{m}$, and the residual is paid to the owner (i-e., $x_{0}=x-x_{m}$ ). The outcome is a function of: 1 ) the invested capital $(q \varepsilon Q), 2)$ the manager's action (a $\varepsilon$ A), 3) the manager's effort, (e $\varepsilon E$ ); and 4) the states of natures $(s \in S)$. Thus, it can be represented as followas:

$x=p(s, a, e, q)$

The output $(x)$ is reported by a designated accounting system or other information sources to both individualsthe principal and the agent- at some cost of reporting, c (r). To be effective, both the designated information system and it's generated signals must be efficient-that is, it should generate quality information which would reduce the amount of uncertainty and would entail the optimal risk sharing. We define this function as" the informational efficiency" role of the agency theory. Consequently, we have:

$x=p(s, a, e, q)-c(r)$

Informational asymmetry problems exist between the agent and the principal. Let $\mathrm{n} \varepsilon \mathrm{N}$ and $\mathrm{m} \varepsilon \mathrm{M}$ denote the information system which is possessed or accessed by the manager and owner respectively. The signals y $\varepsilon Y(Y$ $\varepsilon N$ ) is obtained after the agent's actions and effort, but before $x_{m}$ is determined.

For risk sharing purposes, and devising an efficient control mechanism, the contract should be based on the "observable elements" by both individuals (Demski and Dye, 1999; Pacharn, 2008). These elements are "performance measures" that will be exerted to monitor the agent's output. We define this role as the "system evaluation" role of the agency theory. To illustrate this role mathematically, let $\hat{n}$ denotes the common information in the two systems and $\hat{y}$ the respected common signal. The management function can be represented as $\hat{y}=\hat{n} \quad(\mathrm{~s}, \mathrm{a}, \mathrm{e}, \mathrm{q}, \mathrm{x})$ and $\mathrm{f}=\mathrm{r}(\mathrm{s}, \mathrm{a}, \mathrm{e}, \mathrm{q}, \mathrm{x})$. Consequently, contractual agreement can be characterized as $x_{m}=r(\hat{y}, f)$. Since it is assumed that the outcome $(\mathrm{x})$ is always observed by both individuals, $x$ is included in $\hat{y}$.

Following the agency theory, it is also assumed that both the agent and principal are utility maximizer under Von Neumann-Morgenstern's utility axioms (Demski, 1980; Lan and Heracleous, 2010). The principle is concerned only with his/her net residuals, $x_{0}$, and is riskneutral. However, the agent's utility is centered on his/her pecuniary return, $x_{M}$, as well as his/her act(a) and effort(e) exerted. It also can be represented as additive and differentiable equation as $\mathrm{U}_{\mathrm{M}}\left(\mathrm{x}_{\mathrm{M}}, \mathrm{a}\right)=\mathrm{U}\left(\mathrm{x}_{\mathrm{M}}\right)-\mathrm{V}(\mathrm{a})$. The efforts expended by the agent are assumed to generate disutility to him/her. Incentive problems may arise here because the objectives of the agent and principal can be incompatible. Consequently, the agent might select actions which are more consistent with his/her self-interest, and less consistent with the principal's goals. The agent is assumed to be generally risk and work-averse. We define this role as "behavioral role" of the agency theory.

Under this condition, the expected utility of the manager who exerts effort (e) and action (a), can be represented as follows:

$E\left(U_{M h} \mid a, e, r\right)=\int_{s} U_{M}(r(n(a, e, q, h, s)), e) \phi s(d s)$

If $\mathrm{e}_{\mathrm{h}}^{*}$ (I) represents the management's effort given the contract I and effort $h$, the expected utility of the managers is as follows:

$$
\begin{gathered}
\mathrm{E}\left(\mathrm{U}_{\mathrm{Mh}} \mid \mathrm{e}_{\mathrm{M}}^{*}(\mathrm{I}), \mathrm{I}=\max \underset{\mathrm{a} \in \mathrm{A}}{\mathrm{E}}\left(\mathrm{U}_{\mathrm{Mh}} \mid \mathrm{e}, \mathrm{I}\right)\right. \\
(\mathrm{e} \in \mathrm{E})
\end{gathered}
$$

On the other hand, the expected utility of the owner is the function of:

1) the contract that he/she has signed with management, and 2) his/her estimation concerning the agent's effort during the contract period. If $\mathrm{e}_{\mathrm{h}}^{*}(\mathrm{I})$ represents the owner's estimation of the agent's effort, then the expected utility function of the owner is represented as follows:

$$
\begin{gathered}
\mathrm{E}\left(\mathrm{U}_{0} \mid \mathrm{e}^{*}(\mathrm{I}), \mathrm{I}\right)=\iint_{\mathrm{Hs}} \mathrm{U}_{0}\left(\mathrm{P}\left(\mathrm{s}, \mathrm{e}_{\mathrm{h}}^{*}(\mathrm{I}), \mathrm{q}, \mathrm{h}\right)\right. \\
-\mathrm{r}\left(\mathrm{n}\left(\mathrm{s}, \mathrm{e}_{\mathrm{h}}^{*}(\mathrm{I}), \mathrm{q}, \mathrm{h}\right)\right) \\
\left.-\mathrm{c}\left(\mathrm{s}, \mathrm{e}_{\mathrm{h}}^{*}(\mathrm{I}), \mathrm{q}, \mathrm{h}, \mathrm{n}\right)\right) \\
\phi \mathrm{s}(\mathrm{ds}) \phi_{0}(\mathrm{~h} \mid \mathrm{I}) \mathrm{dh}
\end{gathered}
$$

By solving Equations 4, and 5 simultaneously the Pareto- 
Table 1. Illustration of the management-owner relations in a basic agency model.

\begin{tabular}{lll}
\hline $\mathbf{1}$ & $\mathbf{2}$ & $\mathbf{3}$ \\
\hline $\begin{array}{l}\text { Management and owner select a } \\
\text { contract and information system(s) } \\
\text { cooperatively }\end{array}$ & Management selects & Management and owner jointly observe the \\
& $\begin{array}{l}\text { action (a) } \\
\text { independently }\end{array}$ & $\begin{array}{l}\text { outcome, and management's pay is based } \\
\text { upon a designed contract at time 1 }\end{array}$ \\
\hline
\end{tabular}

optimal contract ${ }^{1}$ can be attained. This type of contracts not only maximizes the utility function of the agent and the principal, but also would lead to efficient allocations of the firm's resources. We define this role, as the "allocation role" of the agency theory.

Much of the early research on agency theory (Demski, 1980; Shavell, 1979, Holmstram, 1979) have attempted to solve the preceding problems. As a result, different cases have been investigated, which provide the optimal control mechanism for each situation. We define this role as "the optimal control monitoring selection" role of the agency theory. This role is explained next.

\section{Case 1: Management's control based on the output}

The primitive scenario of management's control occurs when only output $(x)$ of the agency is expended for monitoring control. This situation is illustrated in Table1.

At time 1, the owner hires a manager in order to obtain the following benefits: 1) to increase the output and, therefore revenues; 2) to acquire management's knowledge, expertise, or information; 3) to obtain such non-pecuniary benefits as affiliation and prestige. Management, on the other hand, maintains a desire to acquire remuneration, a wish to transfer more of the risk to the owner, and a need to satisfy non- pecuniary items.

Management knows how his/her information, knowledge, and skills match the job to be performed. However, the owner cannot appraise these attributes directly with its control monitoring devices (including an accounting information system). If management is hired, at time 2, he/she can independently choose any action or effort level that maximizes his/her utility function. Although the owner cannot directly observe the management's action and effort levels at time 2, the payoff (or outcome) always becomes observable by both - management and owner- at time $3^{2}$. This outcome is a function of management's actions, efforts, and exogenous stochastic variables. The outcome may be revenues, profits, or products and services.

At time 1, the owner and management must also address two issues cooperatively: the kind of information

\footnotetext{
${ }^{1}$ - A Pareto-optimal contract is a contract in which maximizes the expected utility functions of the both individuals - the agent and the principal- and at the same time, provides enough incentives for the agent not to take any actions that jeopardize the principal's benefits.

${ }^{2}$ - This assumption rules out the possibility of initiating contracts that are incompatible with incentive.
}

system(s) to be exerted for characterizing management's control mechanism, and the type of contract to be employed for (a) effecting an efficient risk sharing and (b) providing management with an appropriate incentive. This type of contract is known as a "Pareto-optimal incentive contract" (Namazi, 1985; Pacharn, 2008; Demski et al., 2009).

Mathematically, when an accounting system ex ante reports the value of $(x)$, management's fee schedule for controlling mechanism must depend only on $x$. This dependency, however, interrupts any owner-management risk-sharing arrangements. If, for instance, management is risk-averse and the owner is risk-neutral, the optimal contract based on the output maximizes management's expected utility function without decreasing its welfare and, at the same time, provides management an incentive to take no action that jeopardizes the owner's well being.

Much of the research on agency theory has focused on solving the preceding obstacle, and a plausible solution has emerged. This solution, derived by Spence and Zeckhauser (1971) and Ross (1973), among others, assumes that owner and management have identical attitudes toward risk and that $(x)$ is formally based on (a) and (s). Given the distribution of (s) and using the firstorder condition, one can then determine an optimal fee schedule by applying the calculus of variations to a manager's specified program.

Wilson (1968), Ross (1973), Harris and Raviv (1976, 1978), demonstrate that under these circumstances, the Pareto-optimal fee schedule is linear, consisting of a fixed salary and a variable that designates profit sharing between the owner and management.

When only output is monitored for controlling mechanism, however, the owner cannot assert the effort level of management directly via the accounting information system. Thus, if a poor outcome results, management can always blame it on unfavorable states of nature rather than on lower effort. In agency theory, this unobservability of labor's effort (action) and its effect on the outcome is known as the "moral hazard" (Holmstrom, 1979; Demski and Dye, 1999). A fee schedule that subsumes moral hazard problems, is known as the "second-best solution" (Holmstrom, 1979; Shavell, 1979; and Demski, 1980) because it is based on an imperfect estimate of the agent's effort, and it compensates for the lack of observability of the agent's effort by trading some risk-sharing benefits to stimulate a proper level of effort. This is one disadvantage of a linear fee schedule. 
Demski (1980), however, demonstrates that when management's stewardship function is only based on the outcome $(\mathrm{x})$, if management and owner are both risk neutral, and management possesses sufficient resources to acquire the firm by compensating the owner, establishing a "takeover contract"- which sells the whole firm to the agent and thus leaves no risk sharing-provides the "first-best solution". Consequently, he provides the following lemma:

Lemma 1: In the basic stewardship model with the manager risk neutral, an appropriate takeover contract will produce the first-best solution (p. 107).

$\mathrm{He}$ also maintains that if the manager is work-neutral $(\mathrm{V}(\mathrm{a})=$ constant $)$ and is ready to implement the owner's fee schedule based on a fix amount $r(0)=k^{x}$, the "salary contract" is appropriate. Thus,

Lemma 2: In the basic stewardship model with the manager work-neutral, an appropriate salary contract will produce the first-best solution (p. 107).

These situations, in effect, provide the necessary conditions for designing effective management control systems.

\section{Case 2: Management's control based on the output and agent's action}

In order to alleviate the consequences of the moral hazard, and to improve the performance criterion of the management's control system, the owner and management can select one of two finer accounting systems $\left(\mathrm{n}_{2}\right)$ that reports both the output $(\mathrm{x})$ and management's action (a): (1) an accounting information system that produces an additional signal $(\hat{y})$, which reports a complete observation of the management's effort, or (2) one that extends the amount of accounting data to situations in which incomplete information $(\hat{y})$ about management's action is reported.

In the first case, $\left(\mathrm{n}_{2}\right)$ reports both $(x)$ and the perfect value of (a). Consequently, $r(x, \hat{y})$ can be characterized by establishing a "forcing contract" based on the management's effort (action) level. If management supplies a predetermined effort level observable by the owner, he/she would receive a share based only on the outcome produced. On the other hand, if management fails to exert a proper level of effort, it would get nothing (Harris and Raviv, 1978: 24). Such a fee schedule, which entails optimal risk sharing between the individuals, becomes a "first-best solution" (Shavell, 1979; Demski, 1980; Stevens and Thevarajan, 2010). Demski (1980) has termed this as a "wage contract" and has provided the following lemma:

Lemma 3: In the basic stewardship model with the effort and outcome jointly observed, an appropriate wage contract will produce the first-best solution (p.107).
In addition, when perfect information about the states of nature exists, and the output $(x)$ is observable by both parties, establishing a contract which guarantees a fixed income $\left(\mathrm{k}^{*}\right)$ for the agent would be optimal, as long as he/she exerts his/her best action. In this case, the optimal control mechanism is represented by $\mathrm{r}(\mathrm{s}, \mathrm{x})=\mathrm{x}-\mathrm{p}(\mathrm{s}, \hat{\mathrm{a}}, \overline{\mathrm{q}})+\mathrm{k}^{*}$.

Demski (1980) has termed this fee schedule as the "insurance contract" and provides the following lemma:

Lemma 4: In the basic stewardship model with the state and outcome jointly observed, an appropriate insurance contract will produce the first-best solution (p. 107).

Much of the earlier work in agency theory (Arrow, 1971; Stieglitz, 1975; Shavell, 1979) focused on determining the characteristics of the first-best solution. These characteristics will not, however, be discussed here since they cannot be applied unless management effort is known with complete certainty. As Holmstrom (1979) notes, in real situations, full information about labor's effort is either impossible or prohibitively expensive to obtain.

The fineness of an accounting information system, which is exerted as a potent control mechanism, however, can be enhanced by collecting additional imperfect information about management's effort and skills. Consequently, the owner's endeavor should be reducing the extent of the "moral hazard" and "adverse selection effects". Moral hazard occurs when principal cannot determine the exerted level of the agent's effort. Adverse selection effects is created when the agent claims his/her skill and experience is higher than the actual one, and the principal cannot ascertain and verify if the agent actually has expended his/her ability in the designated job (Demski and Feltham, 1978; Holmstrom, 1979; Demski, et al., 1999). This goal can he achieved by appropriating resources to generate or improve cost effective reports relating to the agent's effort. Since the owner cannot observe management's effort directly, it can conveniently establish management's standard of output and exert this standard to measure ex post production efficiency. This standard or budget can be utilized as a powerful control mechanism. Furthermore, the owner can instruct management to select an optimal level of action. This consideration allows the principal and agent to share the random fluctuations in output optimally. Subsequently, management can be paid a constant amount as a reward for selecting an optimal action. In addition, since the agent is aware that his effort is observable, and his payoff is therefore subject to less random noise, he/she will expend a level of effort that provides the owner with an expected utility higher than when effort is not observable (Diamond and Verrecchia, 1982; Kren and Tyson, 2009).

Observing management's effort, however, is not costless, and perhaps more important, not all additional 
information has positive effects. Infact, additional incomplete information may provide an inaccurate signal concerning management's true effort (Shavell, 1979). Hence, an interesting inquiry arises: Given the new risk, can improvements (in the sense of the Pareto-optimal condition) be made by obtaining additional incomplete information about the management's effort? The answer relies on the value of the additional information.

Holmstrom (1979), for instance, has introduced the "In formativeness principle" to reply to this inquiry. This principle generally states that any information concerning the agent's selected action, effort and skill, although incomplete, should be included in the compensation contracts, as long as the marginal benefits of the information is greater than its marginal costs. In sum, agency theory (Demski and Feltham, 1978; Gjedsdal, 1981, Namazi, 1985, Baiman, 2000) supports collecting additional information about the agent's efforts and skills, because it will improve the fee schedule solution, and will also enhance the precision of the measurement criteria of the management's control systems.

\section{Case 3: Management's control based on the output, agent's action, and additional variables}

This aspect extends the management-owner function to situations in which an accounting information system $\left(\mathrm{n}_{3}\right)$ provides not only the information surrounding the output $(x)$ and action (a), but also an additional signal $\left(y^{*}\right)$ that conveys information about the capital (q) provided by the owner. Assuming that owner has completely delegated decision-making related to the production process to management, and that the amount of (q) will not be altered throughout the production process, the issue becomes how a Pareto-optimal payment schedule between the owner and management can be devised, and given additional incomplete accounting information, what kind of contract a manager should select?

Demski and Feltham (1978) attempted to address these issues by formulating an agency model within a general framework at the aggregate level. They explicitly distinguished the agent's action (a) from the effort (e) and denoted the outcome as $x=p(a, s, q, e)$. Both the owner and management are utility maximizes. The utility function of the manager is formulated on outcome $(x)$ and effort $(\mathrm{e})$, that is. $U_{m}\left(x_{m}, e\right)$. Management's utility function increases with respect to wealth $\left(\partial \mathrm{U}_{\mathrm{m}}() / \partial \mathrm{x}_{\mathrm{m}}>0\right)$; it decreases and is strictly concave with respect to effort $\left(\partial \mathrm{U}_{\mathrm{m}}(0) / \partial \mathrm{e}<0\right.$ and $\left.a U_{m}(0) / \partial x_{m}\right)$; management may be either risk neutral $\left(\partial^{2} U_{m}() / \partial x_{m}^{2}\right)$, or risk-averse $\left(\partial^{2} U_{m}(0) / \partial x_{m}^{2}\right)$. The owner on the other hand, is concerned only with maximizing his/her residual value less information costs $\left(x_{n}\right)$-that is, $x_{0}=x-x_{m}-x_{n}$ where $\left(x_{0}\right)$ is the owner's share from the output-and he is risk neutral $\left(\mathrm{U}_{0}\left(\mathrm{x}_{0}\right)=\mathrm{x}_{0}\right)$.
It is assumed that the control mechanism is designed in such a manner that signals generated by the system $\left(n_{3}\right)$ are jointly observed by both individuals and, therefore, can be expended as a control element. In this case, the domain of the contract is limited to $x_{m}=I\left[\hat{n}_{3}(s, a, q, e)\right]$. Given $\left(I, n_{3}\right)$, labor's behavior can be represented by:

$$
E\left(U_{m} \mid s, a, e, q\right)=\int U_{m}\left[I\left(\hat{n}_{3}(a, s, q, e), a\right] P(s) d s\right.
$$

Let $(\mathrm{e} \mid(\mathrm{l}, \mathrm{a}))$ denote management's optimal effort, given a specific contract, (I) and his/her action; then we have:

$$
\mathrm{E}\left[\mathrm{U}_{\mathrm{m}} \mid \mathrm{e}(\mathrm{I}), \mathrm{I}\right]=\operatorname{Max} \mathrm{E}\left(\mathrm{U}_{\mathrm{m}} \mid \mathrm{e}, \mathrm{I}\right)
$$

The owner's utility, on the other hand, depends on (I) and his/her prediction of management's optimal level of effort, $\mathrm{e}^{*}(\mathrm{I})$; thus, his/her expected value model can be expressed as:

$$
\begin{aligned}
& \mathrm{E}\left(\mathrm{U}_{0}||_{\mathrm{e}}^{*}(\mathrm{I}), \mathrm{I}\right)=\iint \mathrm{U}_{0}\left\{\left(\mathrm{P}\left(\mathrm{a}, \mathrm{s}, \mathrm{e}^{*}(\mathrm{I}), \mathrm{q}\right)-\mathrm{I}\left(\hat{\mathrm{n}}_{3}\left(\mathrm{a}, \mathrm{s}, \mathrm{e}^{*}(\mathrm{I}), \mathrm{q}\right)-\right.\right.\right. \\
& \left.\left.\mathrm{C}\left(\mathrm{a}, \mathrm{s}, \mathrm{e}(\mathrm{i}), \mathrm{q}, \hat{\mathrm{n}}_{3}\right)\right]\right\} . \mathrm{P}(\mathrm{s}) \mathrm{ds} \cdot \mathrm{P}_{\mathrm{e}}(\mathrm{a} \mid \mathrm{I}) \mathrm{da}
\end{aligned}
$$

Where (c) denotes the information cost function; (a), (s), (q), (e ) and (x) are scalars; and the outcome function has the special multiplicative form, $x=P(a, s, q, e) g(s) \psi F(a, q)$, where $g(s)$ is the stochastic component, $\Psi$ is a positive scalar representing the agent's action, and $\mathrm{F}(\mathrm{a}, \mathrm{q})$ is homogeneous, increasing, concave, and differentiable with respect to the designated elements.

To determine the type of optimal incentive contract that should be established between the owner and management, Demski and Feltham (1978) first introduced a new kind of contract called a "budget-based contract" with the following characteristics:

1) The agent's compensation is, in part, a function of some observable attribute(s) of the outcome resulting from his/her action.

2) The contract specifies a budgeted (standard) outcome (attribute) level that partitions the set of possible outcomes into favorable and unfavorable subsets.

3) The agent's compensation consists of two functions, one defined over the favorable subset and the other over the unfavorable subset (p. 337).

Having defined the significant characteristics of the budget-based contracts, they considered the implications of informational asymmetry problems. In particular, they investigated situations it which budget-based contracts ought to be established between the owner and management when moral hazard and adverse selection effects 
Table 2. Characteristics of Pareto-optimal contracts for the moral hazard case.

\begin{tabular}{ll}
\hline A. Costless action or state information & B. Effort and state not observed \\
\hline $\begin{array}{l}\text { Proposition } \mathbf{1} \\
\text { If management's action can be observed without a cost by the } \\
\text { risk-neutral owner, then the competitive equilibrium based on } \\
\text { the wage contracts will be Pareto optimal. }\end{array}$ & $\begin{array}{l}\text { Proposition } \mathbf{4} \\
\text { A necessary condition for a budget based contract to be Pareto- } \\
\text { superior to all alternative contracts in the basic moral hazard is } \\
\text { that the agent be risk averse. }\end{array}$ \\
$\begin{array}{ll}\text { Proposition } 2 & \text { Proposition } \mathbf{5} \\
\text { If the state can be observed by both the risk- neutral owner and } & \text { Given constant stochastic returns for agent and Cobb-Douglas } \\
\text { manager without a cost, and the agent has sufficient wealth to } \\
\text { provide insurance, then the rental and insurance contracts will } \\
\text { be Pareto-optimal. }\end{array}$ & $\begin{array}{l}\text { always exists a dichotomous contract that is Pareto superior to a } \\
\text { linear contract. }\end{array}$ \\
$\begin{array}{ll}\text { Proposition } 3 & \text { C. Effort or state observed at a cost } \\
\text { A necessary condition for a budget- based contract to be } & \text { Proposition } \mathbf{6} \\
\text { Pareto-superior to all alternative contracts in the basic moral } \\
\text { hazard model is that it be costly to observe both labor's effort } \\
\text { and the state. }\end{array}$ & $\begin{array}{l}\text { If the principal is risk neutral and the agent is risk averse, then } \\
\text { there exists a budget-based contract that is Pareto superior to } \\
\text { the linear contracts. }\end{array}$ \\
\hline
\end{tabular}

Table 3. Characteristics of Pareto-optimal contracts for the adverse selection case.

\begin{tabular}{|c|c|}
\hline A. Costless skill or state information & B. Skill and state not observed: \\
\hline Proposition 1 & Proposition 4 \\
\hline $\begin{array}{l}\text { If agent's skill and effort can be observed without a cost by the risk } \\
\text { neutral owner, then the competitive equilibrium based on the skill- } \\
\text { dependent wage contracts will be Pareto- optimal. }\end{array}$ & $\begin{array}{l}\text { A necessary condition for a budget- based contract to be } \\
\text { Pareto-superior to all alternative contracts in the basic } \\
\text { adverse selection model is that it be costly to observe both } \\
\text { agent's skills and state. }\end{array}$ \\
\hline Proposition 2 & Proposition 5 \\
\hline \multirow[t]{2}{*}{$\begin{array}{l}\text { If the state and capital can be without a cost observed by both the } \\
\text { risk neutral owner and manager, and the owner has sufficient } \\
\text { wealth to provide insurance, then the competitive equilibrium based } \\
\text { on rental and insurance contracts will be Pareto-optimal. }\end{array}$} & $\begin{array}{l}\text { Given certain economic assumptions and with each agent's } \\
\text { action, capital, and outcome without a cost observed, there } \\
\text { exists a dichotomous budget contract which is Pareto } \\
\text { superior to the separating linear contracts. }\end{array}$ \\
\hline & C. Effort of State Observed at a Cost \\
\hline Proposition 3 & Proposition 6 \\
\hline $\begin{array}{l}\text { A necessary condition for a budget- based contract to be Pareto- } \\
\text { superior to all alternative contracts in the basic adverse selection } \\
\text { model is that it be costly to observe both agent's skill and the state. }\end{array}$ & $\begin{array}{l}\text { If the principal is risk neutral and the agent is risk averse, } \\
\text { then there exists a budget-based contract that is Pareto } \\
\text { superior to the linear contracts. }\end{array}$ \\
\hline
\end{tabular}

are expected. A summary of the results of this study concerning the moral hazard selection efforts is shown in Table 2 (Namazi, 1985: 130).

Table 2 lists the types of Pareto-optimal contracts that can be offered to management in the presence of the moral hazard under each observability assumption. For example, given proposition 1, wage contracts are efficient. Rental and insurance contracts provide a firstbest solution under proposition 2. Budget-based contracts with costly investigations Pareto-optimally dominate linear contracts under proposition 6.

Similarly, the ADVERSE selection effect case is shown in Table 3 (Namazi, 1985: 138). Hence, these findings can help managerial accountants select an optimal contract from among different modes of alternative contracting, and they provide a useful theoretical basis for designing managerial budgets and control systems.

\section{DISCUSSION AND CONCLUSIONS}

The major purpose of this study was to extricate the role of the agency theory in implementing management's control system. By adapting the agency theory paradigms and contractual agreement frameworks, it was demonstrated that agency theory has posited, at least, the 
following 6 vital roles in this realm:

1) It provides a delegate and precise quantitative and scientific mathematical model to explain why control is important, and therefore, should be exerted in the organization. In effect, it offers a convincing explanation for implementing this powerful managerial accounting technique. This is the "organizational role" of the agency theory.

2) It examines different "performance measures" that must be encompassed in a control system in order to attain a suitable performance. Thus, it solves one of the significant management accountants' obstacles-i.e. what to choose as a performance measures for controlling operations and/or, rewarding the stakeholders. This is part of the "system evaluation" role of the agency theory.

3) It establishes appropriate standards of performance and how are they must be implemented in an attempt to attain Pareto optimality in the organization. Thus, it provides an efficient resource allocation mechanism for the firms. This function is the "allocation efficiency" role of the agency theory.

4) It unambiguously and mathematically demonstrates the significance of various information, and particularly accounting information, in establishing control systems under various conditions of uncertainty. This is the "informational efficiency" role of the agency theory.

5) It encompasses various constituent factors affecting implementation of the efficient control systems. Consequently, the role of pecuniary and non-pecuniary, and behavioral aspects is particularly revealed. This is the "behavior aspects" of the theory.

6) It leads various stakeholders (managers and owners) on how to select a suitable type of contractual agreements in different situations, and provides an optimal control mechanism for each realm. This is the "optimal control monitoring selection" aspect of the agency theory.

Despite of the preceding advantages, the presented agency paradigm was basic, primitive and simple. Recent developments in the domain of the agency theory, (Eldenburg and Krishnan, 2003; Kornish and Levine, 2004), however, it has been extended it to situations in which private information, multiple agents, multiple principles, and multiple objectives are presumed. In addition, the major assumptions of the agency theory, particularly the self-interest behavior, work-aversion, and shirking attitude of the agent, have been questioned, and have entered to be scrutinized under different cultures (Osterman, 2006; Kren and Tyson, 2009). The emergence of empirical research in the agency area has also created a rethinking attitude concerning the agency theory, and has enhanced the existing knowledge in this area, by providing empirical evidence (Dikolli, 2001; Stevens and Thevaranjan, 2010; Demski et al., 2009). While some of these studies have confirmed the agency premises, others have reported the opposite. Hence, more research in this domain, at the theoretical and empirical realm, is suggested for future control studies and endeavors.

\section{ACKNOWLEDGEMENTS}

The authors would like to express his sincere thanks and appreciation to the editor and anonymous referrers of this journal who provided valuable comments, which enhanced the quality of this paper.

\section{REFERENCES}

Alchian AA, Demsetz H (1972). Production, information costs and economic organization. Am. Econ. Rev. pp.777-795.

Anthony RN (1965). Planning and control systems: A framework for analysis. Boston: Harvard Graduate School of Business.

Arrow KJ (1971). Political and economic evaluation of social effects and externalities. in Frontiers of quantitative economics, ed. By $M$. Intriligator (North-Holland).

Baiman S (1982). Agency research in managerial accounting: a survey. J. Account. Lit. (1):154-213.

Baiman S (1990). Agency research in managerial accounting: A second look. Accounting, Organization and Society. 15(4):341-371.

Demski JS (1980). A simple case of indeterminate financial reporting. Information Economics and Accounting Research, ed. By G. Lobo and M. Maher (University of Michigan: Ann Arbor).

Demski JS, Dye RA (1999). Risk, return, and moral hazard. J. Account. Res. 37(1):27-55.

Demski JS, Feltham G (1976). Cost determination: A conceptual approach (Ames: lowa State University Press).

Demski JS, Fellingham JC, Lin HH (2009). Tension relevance. J. Manage. Account. Res. (21):241-248.

Diamond DW, Verrecchia RE (1982). Optimal managerial contracts and equilibrium security prices. J. Financ. pp.275-287.

Dikolli SS (2001). Agent employment horizons and contracting demand for forward-looking performance measures. J. Account. Res. 39(3):481-494.

Eldenburg L, Krishnan R (2003), Public versus private governance: A study of incentives and operational performance. J. Account. Econ. pp.377-404.

Eisenhardt KM (1989). Agency theory: An assessment and review. Acad. Manage. Rev. 14(1):57-74.

Gjesdal F (1981). Accounting for stewardship. J. Account. Res. Spring:208-231.

Harris M, Raviv A (1976). Optimal incentive contracts with imperfect information. Working paper, Carnegie-Mellon University.

Harris M, Raviv A (1978). Some results on incentive contracts with application to education and employment, health insurance, and law enforcement. Am. Econ. Rev. pp.20-30.

Holmstrom BR (1979). Moral hazard and observability. Bell J. Econ. Spring:74-91.

Horngren CT, Datar SM, Rajan M (2012). Cost accounting: A managerial emphasis", 14th edition, Prentice Hall.

Jensen MC, Meckling WH (1976). Theory of the firm: managerial behavior, agency costs and ownership structure. J. Financ. Econ. pp.305-360.

Kaplan R (1984). The evolution of management accounting. Account. Rev. pp.390-418.

Kaplan R, Atkinson AA (2012). Advanced management accounting. Prentice Hall.

Kornish LJ, Levine CB (2004). Discipline with common agency: the case of audit and non-audit services. Account. Rev. 79(1):173-200.

Kren L, Tyson T (2009). Trade-offs in objective and subjective performance evaluation: a case study examining the validity of the agency theory prediction. Manage. Account. Quart. pp.12-23.

Lan L, Heracleous $L$ (2010). Rethinking agency theory: The view from law. Acad. Manage. Rev. 35(2):294-314.

Namazi M (1983). Accounting information and optimal incentive 
contracts in a multi-objective setting. Ph.D. dissertation, University of Nebraska, Lincoln. USA.

Namazi M (1985). Theoretical developments of principal-agent employment contract in accounting: the state of the art. J. Account. Lit. 4:113-163.

Osterman P (2006). Overcoming oligarchy: culture and agency in social movement organizations. Adm. Sci. Quart. 51(4):622-649.

Outley D (1995). Management control, organizational design and accounting information systems. Published in Issues in management accounting, 2nd Edition, Edited by Ashton D, Hopper T, and Scapens RW, Prentice-Hall Europe.

Pacharn P (2008). Accounting choice and optimal incentive contracts: a role of financial reporting in management performance evaluation. Adv. Manage. Account. 171:289-316.

Penno M (1984). Asymmetry of Pre-decision information and management accounting. J. Account. Res. Spring:177-191.

Radner R (1981). Monitoring cooperative agreements in a repeated principal-agent relationship. Econometrica pp.1127-1148.

Ross SA (1973). The economic theory of agency: the principal's problem. Am. Econ. Rev. pp.134-139.
Shavell S (1979). Risk-sharing and incentives in the principal-agent relationship. Bell J. Econ. Spring:55-73.

Spence M, Zeckhauser R (1971). Insurance, information, and individual action. Am. Econ. Rev. pp.380-391.

Stevens DE, Thevaranjan A (2010). A moral solution to the moral hazard problem. Account. Organ. Soc. 35(1):125-139.

Wilson RB (1968). The theory of syndicates. Econometrica pp.119-132.

Zimmerman JL (2010). Accounting for decision making \& control. 7th edition, McGraw-Hill; Irwin. 